\title{
Spatial Variability of PAHs and Microbial Community Structure in Surrounding Surficial Soil of Coal-Fired Power Plants in Xuzhou, China
}

\author{
Jing Ma ${ }^{1,2}$, Wangyuan Zhang ${ }^{2}$, Yi Chen ${ }^{2}$, Shaoliang Zhang ${ }^{1,2}$, Qiyan Feng ${ }^{2}$, Huping Hou ${ }^{2}$ \\ and Fu Chen 1,2,* \\ 1 Low Carbon Energy Institute, China University of Mining and Technology, Xuzhou 221008, Jiangsu, China; \\ jingma2013@cumt.edu.cn (J.M.); slzhang@cumt.edu.cn (S.Z.) \\ 2 School of Environment Science and Spatial Informatics, China University of Mining and Technology, \\ Xuzhou 221008, Jiangsu, China; zwy2014zs@126.com (W.Z.); lucychenzqm@163.com (Y.C.); \\ fqycumt@126.com (Q.F.); hphou@163.com (H.H.) \\ * Correspondence: chenfu@cumt.edu.cn; Tel.: +86-5168-388-3501
}

Academic Editor: Yu-Pin Lin

Received: 19 April 2016; Accepted: 25 August 2016; Published: 2 September 2016

\begin{abstract}
This work investigated the spatial profile and source analysis of polycyclic aromatic hydrocarbons (PAHs) in soil that surrounds coal-fired power plants in Xuzhou, China. High-throughput sequencing was employed to investigate the composition and structure of soil bacterial communities. The total concentration of 15 PAHs in the surface soils ranged from 164.87 to $3494.81 \mu \mathrm{g} / \mathrm{kg}$ dry weight. The spatial profile of PAHs was site-specific with a concentration of 1400.09-3494.81 $\mathrm{gg} / \mathrm{kg}$ in Yaozhuang. Based on the qualitative and principal component analysis results, coal burning and vehicle emission were found to be the main sources of PAHs in the surface soils. The phylogenetic analysis revealed differences in bacterial community compositions among different sampling sites. Proteobacteria was the most abundant phylum, while Acidobacteria was the second most abundant. The orders of Campylobacterales, Desulfobacterales and Hydrogenophilales had the most significant differences in relative abundance among the sampling sites. The redundancy analysis revealed that the differences in bacterial communities could be explained by the organic matter content. They could also be explicated by the acenaphthene concentration with longer arrows. Furthermore, OTUs of Proteobacteria phylum plotted around particular samples were confirmed to have a different composition of Proteobacteria phylum among the sample sites. Evaluating the relationship between soil PAHs concentration and bacterial community composition may provide useful information for the remediation of PAH contaminated sites.
\end{abstract}

Keywords: polycyclic aromatic hydrocarbons; spatial distribution; source apportionment; high-throughput sequencing; soil microbial community

\section{Introduction}

As an important class of persistent organic pollutants (POPs), polycyclic aromatic hydrocarbons (PAHs) are mainly originated from incomplete combustion of fossil fuels, forest fires, crop straw and other organic materials that continuously burn [1,2]. The derivatives from the diagenesis of crude oil and organic matter under anoxic conditions are also the main PAH sources [3]. PAHs are ubiquitous environmental contaminants which are widely distributed in various environments, such as the atmosphere, water, soils and sediments [4,5]. As a rapidly developing country, China has the highest PAH emissions in the world. PAs emission in China was around $114 \mathrm{Gg}$ in 2004, constituting $22 \%$ of total global emissions [6]. 
Due to the carcinogenic properties and persistence of PAHs in the environment, many countries have taken efforts in reducing PAH emissions. Understanding the contribution of PAH emission sources is important for proper management of PAH levels in the environment. The study of $\mathrm{PAH}$ distribution in representative locations can assist in understanding the relation between PAH characteristics and their anthropogenic influence. Natural (such as oil seeps and forest fires) and anthropogenic (such as fossil fuels and combustion) inputs can be traced when PAHs are used alongside with related hydrocarbon marker compounds [7]. The source discrimination of PAHs is facilitated by many approaches, such as PAH ratio methods [8], multivariate analysis [9] and isotope ratio mass spectrometry [10]. Diagnostic ratios can be used for qualitative analysis of various PAH component sources and can primarily give valuable information primarily when there are one or two main sources. However, in the vast majority of cases, more details about the source apportionment are essential for controlling PAH pollution. It has been reported that it is difficult for finer differentiation of possible combustion sources due to the overlap. It has been mainly confined to the laboratory or urban locations [11]. Principal component analysis (PCA) provides a recognition capability, which could improve the source discrimination. PCA is a commonly used tool for multi-variable analysis. However, it is not restricted to the study of receptor model in the research of environmental source apportionment [12].

Once introduced into the soil, PAHs can be decomposed via biotic or abiotic processes, or it can be transferred to soil profiles and groundwater through runoff and leaching [3]. As the most abundant and diverse groups of soil microorganisms, bacteria play an indispensable role in soil ecology, particularly due to their central role in decomposition. Due to their enormous metabolic versatility, they also serve as keystones in biogeochemical cycling [13]. Microbial degradation is a primary process occurring in the natural PAH depletion processes. Bacteria that have excellent PAH-degrading ability are widespread in various environmental media. According to several reports, indigenous microbial communities are important for the success of bioremediation. However, little is known about the difference of microbial composition and structures among the real, historically contaminated soil [14]. Adequate information of microbial consortia structure is useful for monitoring the occurrence of real time biodegradation processes, as well as for carrying out accurate risk assessment in situ. Studies on bacterial community structure associated with bioremediation of PAH-contaminated soils have been reported using traditional standard biochemical tests [15]. Most soil microorganisms cannot be cultivated at present by laboratory approaches [16]. Therefore, several molecular biological techniques such as terminal restriction fragment length polymorphism (T-RFLP) and polymerase chain reaction denaturing gradient gel electrophoresis (PCR-DGGE) have been employed to characterize bacterial community structures $[17,18]$. However, unlike the DGGE method, the T-RFLP technique could not be used for map hybridization or direct cloning and sequencing analysis. The single enzyme digestion fragment is not accurate enough to identify the genus level in the database. In addition, the experimental procedures for DGGE are cumbersome and time consuming. Some analyzing fragments are easily lost in the repeated PCR process of DGGE. Also, these expensive and time-costly techniques can only provide limited information on community structures. In recent years, high-throughput sequencing techniques, such as Illumina sequencing, have enabled more comprehensive detection of microbial community changes and minor populations $[19,20]$. This approach has been used to decipher microbial communities in distinct samples, such as samples taken from polychlorinated biphenyl contaminated environments [21], river water [22] and iron mining soil [23].

Xuzhou is the most important coal production base and an important thermal power plant base in east China. It has more than 80 years of history in producing and using coal. It is generally believed that coal combustion in coal-fired power plants is the main source of $\mathrm{PAH}$ pollution in surrounding farmland. However, with the rapid development of automobiles in China, vast petroleum consumption overlaps with human-intensive activity areas. Therefore, it is crucial to the repair strategy formulation to determine whether or not coal combustion is the only pollution source for coal-fired power plants in the surrounding farmland. Based on these reasons, this work investigated the surrounding soil of 
coal-fired power plants to confirm the source and to provide a scientific basis for soil remediation. Moreover, illumina sequencing was applied to examine microbial community profiles in different sampling sites. This study is intended to provide broad insights for assessing the impact of coal-fired power plants on PAHs emission and surrounding environments.

\section{Materials and Methods}

\subsection{Site Description and Sampling}

Figure 1 demonstrates the locations of sampling sites. These location sites include the following: there were seven samples (px1-px7) collected from the Datun electric power plant, three samples (hr1-hr3) near the Huarun power plant, three samples (dt1-dt3) along the Datang power plant, three samples (hm1-hm3) along the Huamei plant, three samples (yz1-yz3) near the Yaozhuang power plant and four samples (qt1-qt4) near the Quantai power plant.

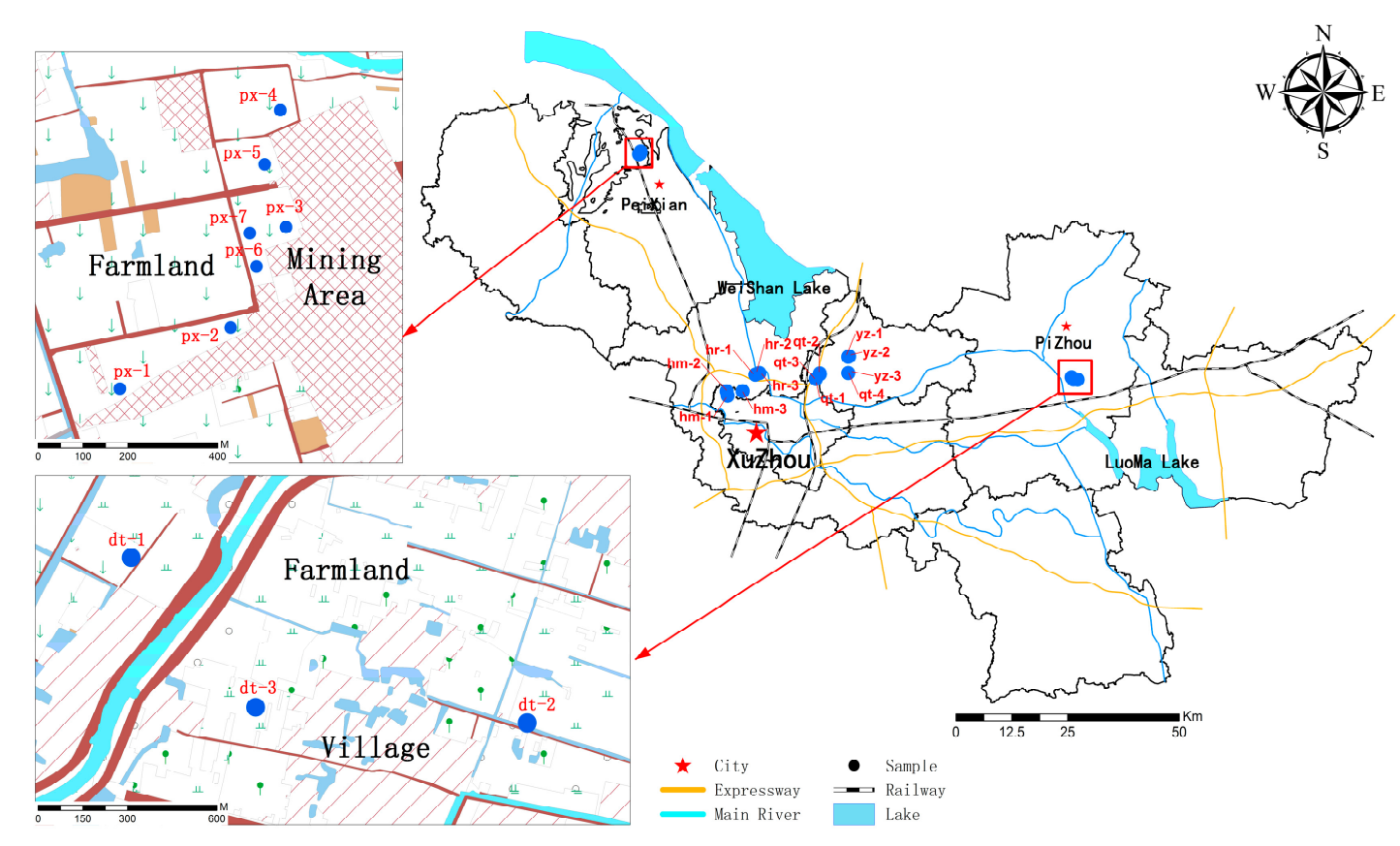

Figure 1. Map showing the sampling locations in Xuzhou city.

Soil samples were collected in November 2014. The top $10 \mathrm{~cm}$ layers were carefully removed with an iron shovel. All samples were packed into aluminum boxes and immediately stored at $4{ }^{\circ} \mathrm{C}$ just for 1-3 days before being extracted. After air-drying at room temperature, the soils were sieved through a 100-mesh sieve. Total organic matter (TOM) was determined through the Walkley-Black wet oxidation method [24].

\subsection{Chemicals}

A mixture of 16 USEPA priority PAHs standards solution [naphthalene (Nap), acenaphthylene (Acy), acenaphthene (Ace), fluorene (Fle), phenanthrene (Phe), anthracene(Anth), fluoranthene (Fla), pyrene (Pyr), benzo[a]anthracene $(\mathrm{BaA})$, chrysene $(\mathrm{Chr})$, benzo[b]fluoranthene $(\mathrm{BbF})$, benzo[k]fluoranthene (BkF), benzo[a]pyrene $(\mathrm{BaP})$, indeno[1,2,3-c,d]pyrene (Ind), dibenz [a,h]anthracene (DBA), and benzo[g,h,i]perylene (BgP)] was purchased from TCI Development Co., Ltd. (Beijing, China). All organic solvents are HPLC grade and purchased from SK Chemicals (Ulsan, Korea). In order to exclude impurities before use, analytical-grade anhydrous $\mathrm{Na}_{2} \mathrm{SO}_{4}$ and silica gel were activated at $320^{\circ} \mathrm{C}$ to exclude impurities before use. 


\subsection{PAH Analysis}

One gram of sieved soil was combined with a $4 \mathrm{~mL}$ mixture of dichloromethane and acetone $(v: v, 1: 1)$ and then sonicated for $30 \mathrm{~min}$. The process was repeated three times by removing the extract and adding fresh solvent. All extracts were combined and concentrated by rotary evaporation. Then, eluting through a chromatography column, which was filled with silica gel and anhydrous $\mathrm{Na}_{2} \mathrm{SO}_{4}$, purified them. The elution liquid was dried under nitrogen, and the residue was dissolved in $1 \mathrm{~mL}$ acetonitrile for HPLC analysis [2].

The PAHs were analyzed by HPLC (Shimadzu-UFLC-10A, Shimadzu (China) Co., Shanghai, China) with a fluorescence detector. The PAH special column (Waters, $250 \mathrm{~mm} \times 4.5 \mathrm{~mm}, 5 \mu \mathrm{m}$ ) was packed into the analyzer. The injection volume was only $1 \mu \mathrm{L}$. Also, the column temperature was $35^{\circ} \mathrm{C}$. The gradient operation procedure was conducted as follows: At the beginning, $55 \%$ acetonitrile was used, $10 \mathrm{~min}$ later, $70 \%$ acetonitrile was used for a linear gradient at $100 \%$ acetonitrile for $15 \mathrm{~min}$. This was kept for $5 \mathrm{~min}$ at 100\% acetonitrile. A linear gradient ( $2 \mathrm{~min}$ ) back to starting conditions was followed by a $3 \mathrm{~min}$ run to stop. In this study, a fluorescence detector quantified 15 PAHs, excluding acenaphthylene.

In this study, the Phe/Anth, Fla/Pyr, Fla/(Fla + Pyr) and Ind/(Ind + BgP) values were used to determine the PAH sources.

\subsection{Microbial Community Analyses}

According to the instruction manual of the FastDNA ${ }^{\mathrm{TM}}$ SPIN kit, DNA was extracted from $0.5 \mathrm{~g}$ soils (MP Biomedicals, Solon, OH, USA) in duplicate which have been stored at $4{ }^{\circ} \mathrm{C}$. Using an Eppendorf thermal cycler (Model 5332), the V4 region of bacterial 16S rRNA genes were amplified. The temperature program consisted of initial denaturing at $98{ }^{\circ} \mathrm{C}$ for $5 \mathrm{~min}$. This was followed by 25 cycles at $98{ }^{\circ} \mathrm{C}$ for $30 \mathrm{~s}, 50{ }^{\circ} \mathrm{C}$ for $30 \mathrm{~s}, 72{ }^{\circ} \mathrm{C}$ for $30 \mathrm{~s}$. Then there was a final extension step at $72{ }^{\circ} \mathrm{C}$ for $5 \mathrm{~min}$. The primer set for the amplification was $520 \mathrm{~F}$ (5'-barcode + GCACCTAAYTGGGYDTAAAGNG-3') and 802R (5'-TACNVGGGTATCTAATCC-3'). The barcode was a seven-base sequence unique to each sample.

The PCR reaction was conducted in triplicate in a $25-\mu \mathrm{L}$ mixture containing $5 \mu \mathrm{L}$ of $5 \times \mathrm{Q} 5$ Reaction Buffer, $5 \mu \mathrm{L}$ of $5 \times$ Q5 GC high Enhancer, $2 \mu \mathrm{L}$ of $2.5 \mathrm{mMdNTPs}, 1 \mu \mathrm{L}$ of each primer $(10 \mu \mathrm{M})$, $0.25 \mu \mathrm{L}$ of Q5 Polymerase, $8.75 \mu \mathrm{L}$ of sterilizing ultrapure water and $2 \mu \mathrm{L}$ of template DNA $(20 \mathrm{ng} / \mu \mathrm{L})$. Three PCR products per sample were pooled and purified with the AxyPrep DNA Gel Extraction Kit (Axygen Biosciences, Union City, CA, USA) in accordance with the instruction manual. Quantification of purified PCR product was performed with a Quant-iTPico Green dsDNA Assay Kit (Invitrogen, Carlsbad, CA, USA). The purified amplicons were pooled in equimolar and paired-end sequenced $(2 \times 300 \mathrm{bp})$ on an IlluminaMiSeq platform (Personalbio, Shanghai, China) according to standard protocols. Raw FASTQ files were de-multiplexed and quality-filtered using QIIME (version 1.7.0) with the following criteria: (1) 300-bp reads were truncated at any site that acquired an average quality score of $>20$ over a 10-bp sliding window. Truncated reads shorter than $150 \mathrm{bp}$ were discarded; (2) reads that contain ambiguous characters and two nucleotides that mismatched in primer matching were removed; (3) according to overlapped sequences, overlapping sequences that are longer than $10 \mathrm{bp}$ would be assembled. Unassembled reads were discarded. Operational taxonomic units (OTUs) having $97 \%$ similarity were clustered using the Uparse soft (version 7.1). The Uchime method was used to identify and remove the chimeric sequences [23]. Greengene was used as the annotation database [25]. Sequences that could not be allocated into any known groups were defined as others.

\subsection{Data Analyses}

PCA was employed to analyze the data groups of PAHs concentrations in order to compare the profiles of each potential PAH source using SPSS 18.0 software (Cabit Information Technology Co., Shanghai, China). Redundancy analysis (RDA) with the Monte Carlo permutation's test 
(499 permutations) was used to evaluate the correlation between soil environmental factors and bacterial community structures through the use of the software Canoco (Cabit Information Technology Co., Shanghai, China) for Windows 4.5.

\section{Results and Discussion}

\subsection{Spatial Distribution of PAHs in the Surface Soil}

The contamination level of PAHs in soil can be divided into four classes: no contamination (total PAHs concentration $<200 \mu \mathrm{g} / \mathrm{kg}$ ), slight contamination ( $200<$ total PAHs concentration $<600 \mu \mathrm{g} / \mathrm{kg}$ ), moderate contamination $(600<$ total PAHs concentration $<1000 \mu \mathrm{g} / \mathrm{kg})$ and severe contamination (total PAHs concentration $>1000 \mu \mathrm{g} / \mathrm{kg}$ ) [26]. The condition of surface soils can reflect the current soil contamination status.

As shown in Figure 2, the total concentration of 15 PAHs in soils ranged from 164.87 to $3494.81 \mu \mathrm{g} / \mathrm{kg}$ dry weight with an average concentration of $1089.69 \mu \mathrm{g} / \mathrm{kg}$. According to the grading criteria, the PAHs pollution levels in the study area rangedfrom no pollution to severe pollution. At sites px6 and yz3, two highest PAHs concentration were observed (3412.64 and $3494.81 \mu \mathrm{g} / \mathrm{kg}$ ). Compared with the PAH concentrations reported in farmland or suburb soil of Korea $(236 \mu \mathrm{g} / \mathrm{kg})$, Switzerland

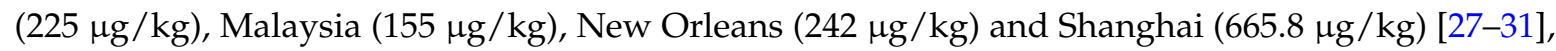
the average concentration of $1089.69 \mu \mathrm{g} / \mathrm{kg}$ found in this study was much higher. However, compared with the PAH concentration of $1840 \mu \mathrm{g} / \mathrm{kg}$ in urban surface soil of Tianjin [32], the PAH concentration in this study was lower. According to the soil quality standard of Canada, the reference value of BaP in agricultural land is $100 \mu \mathrm{g} / \mathrm{kg}$ [33]. BaP has also been classified as group 1 toxic in regard toits carcinogenicity to humans by the IARC (International Agency for Research on Cancer) [34]. In this work, BaP concentrations in five samples (px4, px6, yz1, yz2 and yz3) exceeded the reference value (Figure 2).

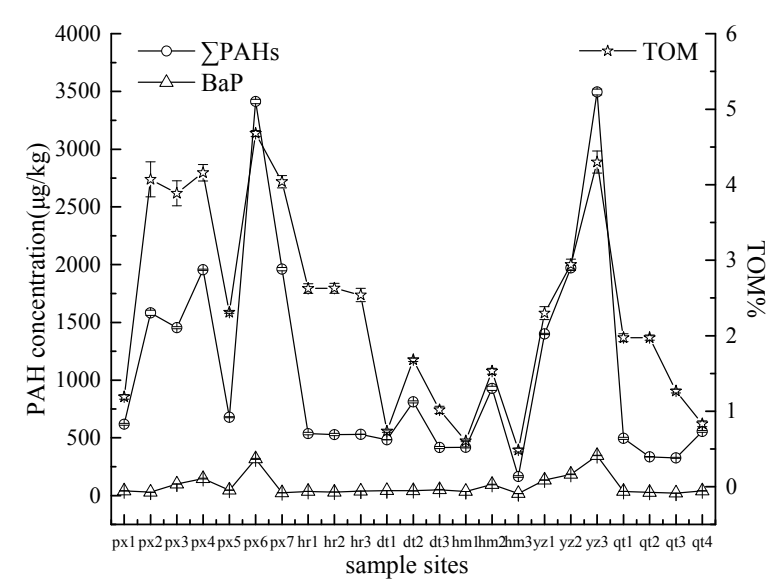

Figure 2. PAHs concentrations and TOM content in each soil sample (see supplementary material).

TOM is an important factor that can impact the transport and fate of PAHs in soils [11]. The relatively low concentrations of PAHs at power plants $\mathrm{hr}, \mathrm{dt}, \mathrm{hm}$ and $\mathrm{qt}$ showed consistentlow levels of TOM (Figure 2). A linear regression analysis indicated that the total concentrations of PAHs were significantly correlated with the TOM contents $(r=0.894, p<0.01)$. However, the relatively low concentration of PAHs at site px 5 with higher TOM content suggested that there existed other factors, such as the application of livestock manure, which may affect TOM levels.

\subsection{Source Analysis via PAHs Constitution}

According to ring numbers, 15 PAHs were classified into three classes: 2-3 ring, 4-ring, and 5-6 ring compositions. These three classes represented low, medium and high molecular weight PAHs, 
respectively. Figure 3 shows the composite model of 15 PAHs. 4-ring PAHs comprised more than $50 \%$ of the total PAHs in all sampling sites, in particularly sites $\mathrm{dt}, \mathrm{hm}$ and $\mathrm{yz}$, which all had two samples with more than 75\% 4-ring composition. For the composition of 2-3 ring and 5-6 ring PAHs, significant discrepancies were detected between sampling sites. Sites px and hm had higher 5-6 ring PAHs composition, while sites hr and qt had higher 2-3 ring composition. These findings indicated that there may be different sources for the PAHs in the soils surrounding different sampling sites. The component percentages of PAHs at sites $\mathrm{hr}$ and qt were similar, suggesting their similar pollution sources. Relative to low molecular weight PAHs (2-3 rings), PAHs with higher molecular weights ( $\geq 4$ rings) adsorb more easily on particulate matter, such as soil particles [35].

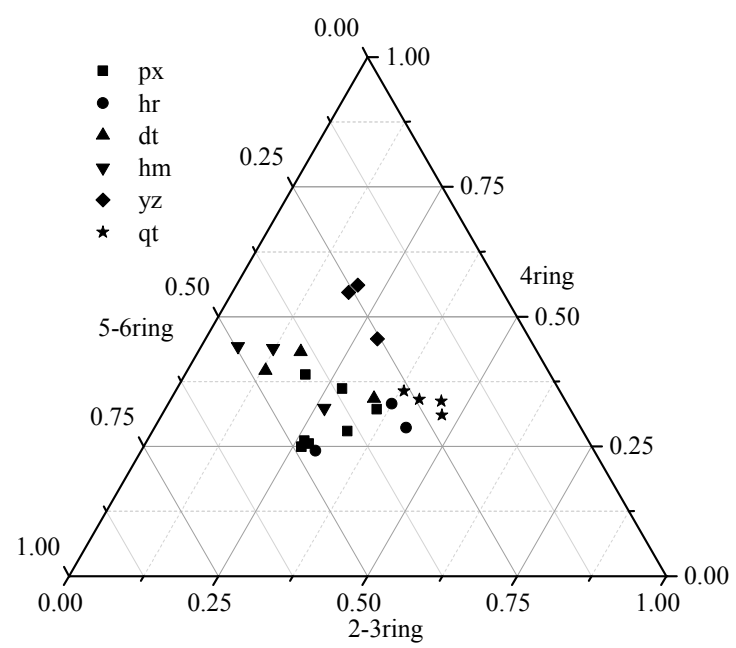

Figure 3. Triangle graph of percentage density for 15 PAHs in the sampling sites.

\subsection{Qualitative Research of PAHs Sources}

The analysis and confirmation of PAHs sources are important to regulate and manage their input, as well as their distribution liability for remediation activity. Based on the characteristics of PAHs compositions and allocation patterns, the sources of anthropogenic PAHs that were formed primarily through emission and combustion of incomplete combusted materials, can be differentiated by individual PAH ratios [8].

As isomers, Anth is thermodynamically more unstable than Phe. The Phe/Anth value $>10$ suggests petrogenic contamination, whereas the value $<10$ implies a pyrolytic source [11]. Pyr is thermodynamically more stable than Fla. Fla/Pyr $>1$ is a feature of the pyrolytic process, while $\mathrm{Fla} / \mathrm{Pyr}<1$ indicates a petroleum origin [7]. As shown in Figure 4a, the Phe/Anth ratios of soil samples ranged from 7.58 to 47.23 . All the samples had Phe/Anth ratios higher than 10, except for sites $\mathrm{px}, \mathrm{dt}$ and $\mathrm{hm}$. This suggested that soil PAHs might be mainly from petrogenic sources. Fla/Pyr values in sites px, $\mathrm{dt}, \mathrm{hm}$ and qt were mostly less than 1 , indicating petrogenic sources of PAHs. This was in agreement with the results of Phe/Anth ratios (Figure 4a). However, the range of Fla/Pyr ratios in samples of sites hr and yz was from 0.94 to 1.24, suggesting a mix of petrogenic and pyrogenic sources.

For Fla/(Fla + Pyr), a ratio $<0.40$ suggests petrogenic origins, a ratio $>0.50$ implies coal, grass, and wood combustion origins, and a ratio of $0.40-0.45$ has been described for gasoline engine exhausts [8]. Different ratios of Ind/(Ind $+\mathrm{BgP}$ ) have been connected to diesel and gasoline vehicles [36]. A ratio below 0.20 is ascribed to petrogenic origins. A ratio above 0.50 indicates wood and coal combustion, whereas the ratio between 0.20 and 0.50 is a trait of petroleum burning performance. As shown in Figure $4 \mathrm{~b}$, the ratios of Fla/(Fla + Pyr) in all sampling sites were higher than 0.40 , except for one sample from site $\mathrm{dt}$, with an average value of 0.49 . This suggested that these sites had the mixed pattern of petroleum and biomass burning sources. Several samples from site px had the ratio of Fla/(Fla + Pyr) between 0.40 and 0.45 , which implied there was a gasoline fuel combustion source. Also as shown in 
Figure $4 \mathrm{~b}$, the ratio of Ind /(Ind $+\mathrm{BgP})$ was mostly lower than 0.50 , particularly, the ratio for sites qt and px were lower than 0.20 , indicating petrogenic origins. The Ind/(Ind $+\mathrm{BgP})$ ratio of samples from site $\mathrm{hr}, \mathrm{dt}$ and $\mathrm{hm}$ was mostly between 0.20 and 0.50 , suggesting petroleum burning sources. According to PAHs source patterns revealed by the specific values of Phe/Anth, Fla/Pyr, Fla/(Fla + Pyr) and Ind /(Ind + BgP), PAHs in the sampling sites were primarily from the mixed sources of petroleum and petroleum combustion.

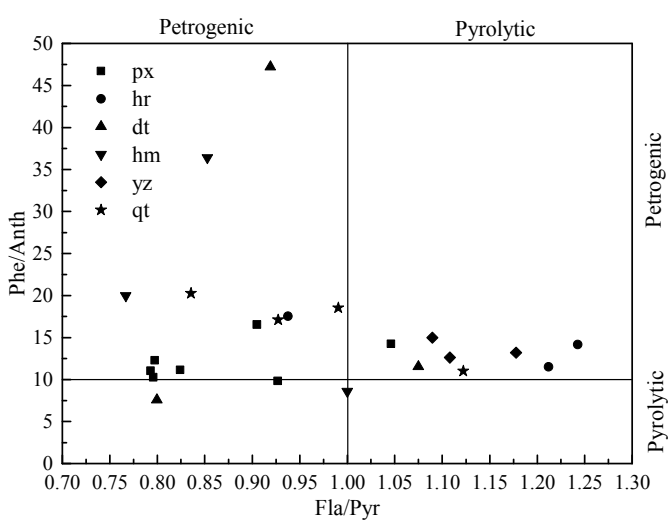

(a)

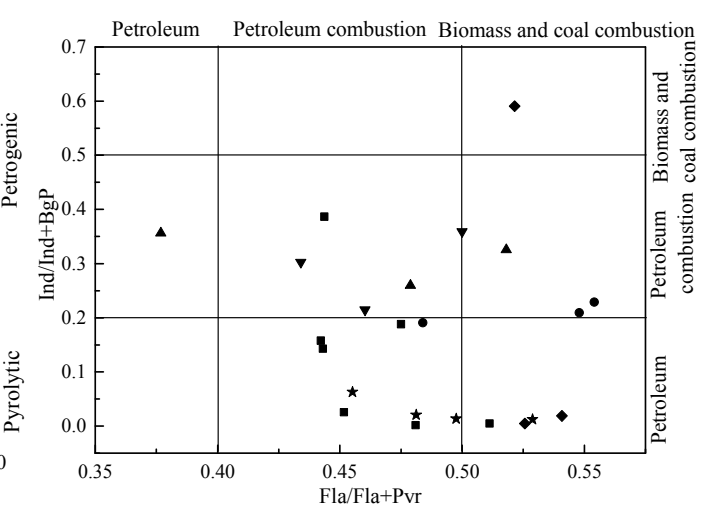

(b)

Figure 4. Source analysis of PAHs through diagnostic ratios. (a) Plot of Fla/Pry vs. Phe/Anth; (b) Plot of Fla $/($ Fla + Pyr $)$ vs. Ind / (Ind + BgP $)$.

\subsection{Source Estimates by PCA}

The objective of PCA is to perform the diversification of PAHs concentrations among sampling sites with the minimum number of factors. The weighted linear combination of the original variablesis the first factor accounting for the greatest variability. Each subsequent factor is responsible for less variability than the former one.

The results of PCA based on PAHs concentrations are listed in Table 1. Three principal components (PCs) were extracted for soils, which accounted for more than $97 \%$ of the variance in the data set. The cumulative variances occupied $88.236 \%$ of the total variation. The three factors were $58.132 \%$, $22.334 \%$, and $7.770 \%$, respectively. Each variation's load value $>0.7$ was highlighted in red bold face.

Table 1. Rotated composition loading values of three principal components (PCs) for PAH compositional analysis.

\begin{tabular}{cccc}
\hline Variable & PC1 & PC2 & PC3 \\
\hline Nap & 0.423 & $\mathbf{0 . 7 2 7}$ & 0.381 \\
Ace & 0.573 & 0.165 & -0.032 \\
Fle & $\mathbf{0 . 8 1 6}$ & 0.348 & -0.391 \\
Phe & $\mathbf{0 . 9 3 2}$ & 0.153 & -0.243 \\
Anth & $\mathbf{0 . 9 3 3}$ & 0.212 & -0.149 \\
Fla & $\mathbf{0 . 8 5 2}$ & -0.518 & -0.042 \\
Pyr & $\mathbf{0 . 9 3 5}$ & -0.343 & -0.037 \\
BaA & $\mathbf{0 . 9 2 5}$ & -0.367 & -0.012 \\
Chr & $\mathbf{0 . 7 4 1}$ & -0.560 & 0.269 \\
BbF & $\mathbf{0 . 9 4 2}$ & 0.288 & -0.046 \\
BkF & 0.572 & -0.762 & 0.281 \\
BaP & $\mathbf{0 . 8 9 4}$ & -0.263 & -0.022 \\
Ind & 0.623 & $\mathbf{0 . 7 3 4}$ & -0.152 \\
DBA & 0.443 & 0.345 & $\mathbf{0 . 7 5 4}$ \\
BgP & 0.452 & 0.616 & 0.192 \\
Explained variance $(\%)$ & 58.132 & 22.334 & 7.770 \\
\hline
\end{tabular}

Note: PCA loading values higher than 0.7 are in bold. 
Factor 1 is heavily weighted by Fle, Phe, Anth, Fla, Pyr, BaA, Chr, BbF and BaP. Previous studies reported the following as dominant, coal combustion profiles: Fla, Pyr, Phe, Anth and BaA [11,37]. Thus, factor 1 seemed to be associated with coal burning.

Factor 2 is predominately weighted by Nap and Ind. Nap is the lightest PAHs quantified, which could be related to the unburned fossil fuels and other sources [38]. Ind has been detected from both diesel and gas vehicle exhaust [39]. BgP, the third highest loading value of factor 2, has been confirmed as indicators of automobile emission [40]. Therefore, factor 2 mainly represents vehicle emissions.

Factor 3 shows a good relevance to DBA, which has been reported to be related to automotive engine exhaust [41].

Generally, the PCA results were in accordance with the results depicted by diagnostic ratios. The PAHs in most soil samples were from both coal combustion and vehicle exhaust. Also, PCA results indicated that PAHs distribution in the soil samples could be related to the surrounding coal-fired plants.

\subsection{Bacterial Taxonomy Composition}

The bacterial OTUs obtained from Illumina sequencing of 16S rRNA genes were classified into 35 different phyla or 254 orders. Figure 5a showed that Acidobacteria, Actinobacteria, Bacteroidetes, Chloroflexi, Gemmatimonadetes, Planctomycetes, Proteobacteria and Verrucomicrobia phyla accounted for more than $80 \%$ of the total reads in every sample. Phyla that occupied less than $1 \%$ of the bacterial communities were not shown. Proteobacteria was the most abundant phylum (Figure 5a), ranging from $15.1 \%$ to $36.6 \%$ in the samples. Acidobacteria, the second most abundant phylum, occupied about $15.6 \%$ in all samples. In general, bacterial community structures varied among different sampling sites (Figure 5a). The trend was more evident as revealed by RDA analysis with samples that came from around the same power plants grouped nearer to each other (Figure 6).

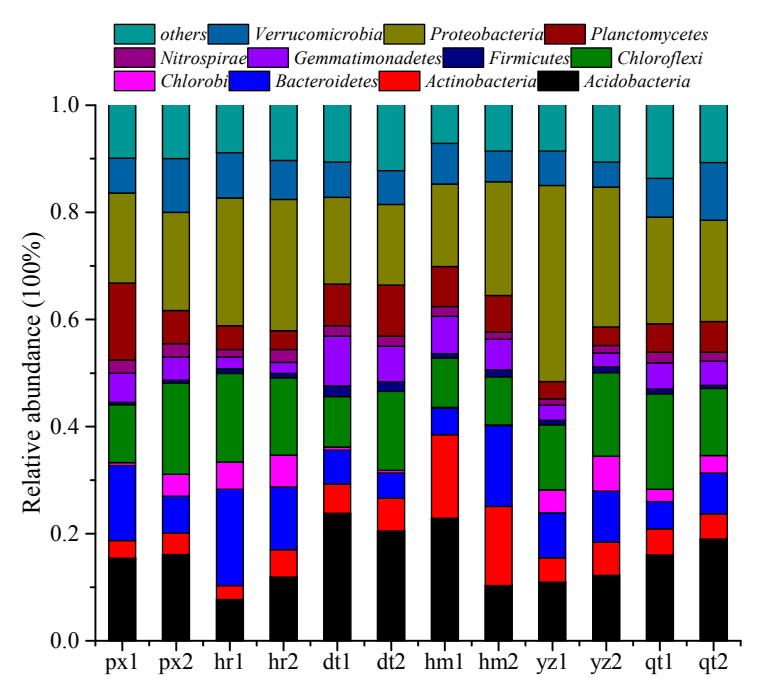

(a)

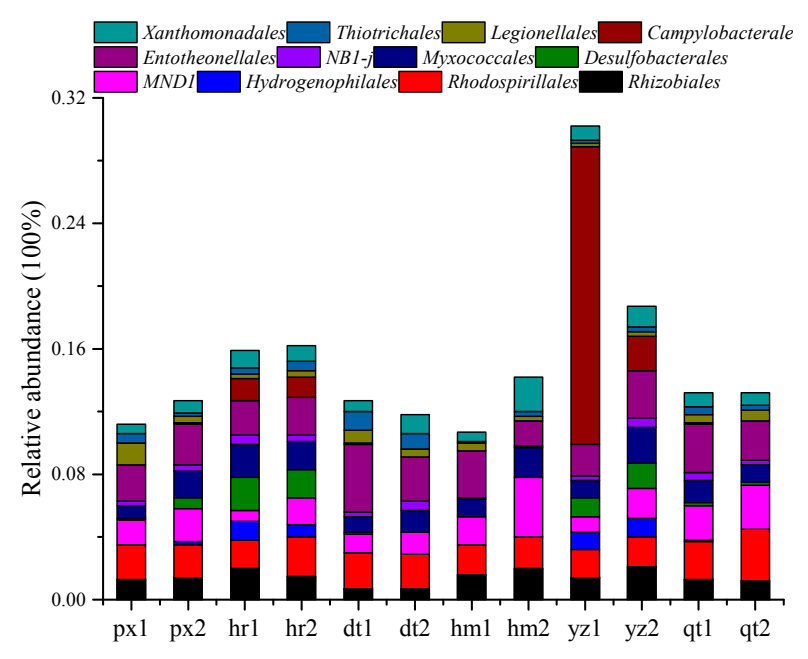

(b)

Figure 5. Taxonomic distributions of 12 soil samples. (a) Phylum profile; (b) Order distribution of phylum Proteobacteria.

The orders of Campylobacterales, Desulfobacterales and Hydrogenophilales from phylum Proteobacteria showed the most obvious distinction of relative abundances among the sampling sites (Figure $5 b$ ). Relative abundances of the three orders were higher in sites hr and yz than others. It has been reported that Desulfobacterales are sulfate reducing bacteria and strictly anaerobic [42]. In contrast, the relative abundances of Rhodospirillale sand Entotheonellales were similar across all the samples. Bacterial consortia enriched from natural communitieshad been reported with reduced complexity. 
This facilitated the relationship between specific populations and functions. Sun et al. [43] identified Alphaproteobacteria (Rhizobium) and Betaproteobacteria (Hydrogenophaga) as the most abundant bacterial components of a pyrene-degrading consortium. Jones et al. [44] also identified that Cupriavidus (Betaproteobacteria) and Luteimonas (Gammaproteobacteria) had a close correlation with benzo(a)pyrene cometabolism in the PAHs polluted soil. Getting information about the response of community members to the stimulation can guide the interpretation and development of remediation approaches. Handley et al. [45] employed a high-density microarray (PhyloChip) to comprehensively determine community membership and abundance patterns among a suite of samples associated with uranium bioremediation experiments. Results showed that Campylobacteriales thrived as a response to acetate amendments and they were associated with Fe (III) and sulfate reduction. Zhao et al. [46] have detected Campylobacteriales in reactors with multiple electron acceptors, under sulfur cycling conditions. It was also reported that Campylobacteriales were detected in wastewater, microbial fuel cells (MFCs) and microbial electrolysis cells (MECs) studies [47]. All these studies imply that Campylobacteriales have a significant role in decomposing organic matters. Higher relative abundances of Campylobacterales, Desulfobacterales and Hydrogenophilales in sites hr and yzmight be related to higher PAH concentration. The results also suggested that we might get high efficiency degrading strains from yz sites.

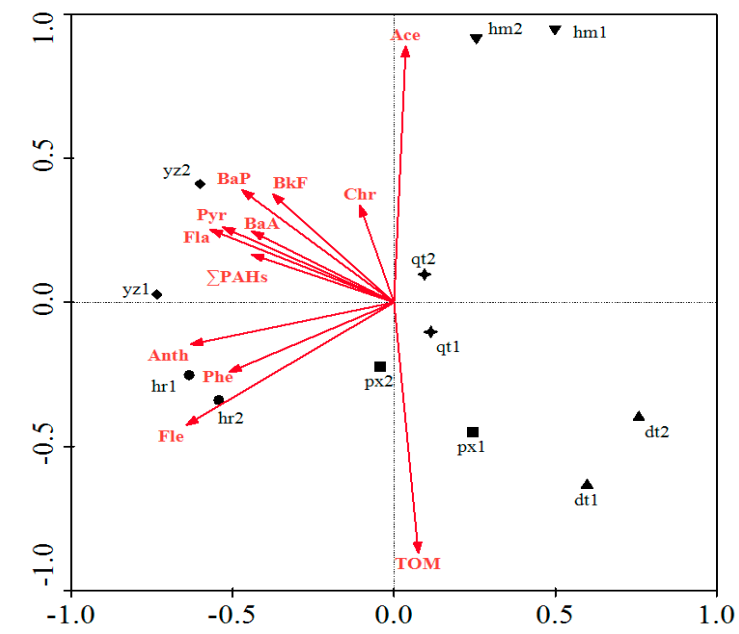

(a)

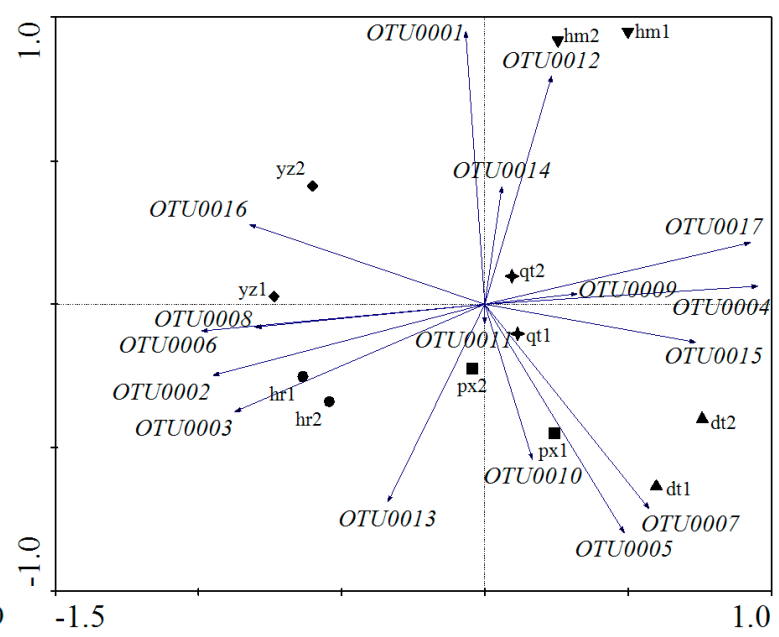

(b)

Figure 6. Redundancy analysis showed the correlation between bacterial consortia and soil environment factors (a) and some frequent OTUs of phylum Proteobacteria (b).

This study confirms the important role of Proteobacteria in PAHs polluted soils. In this study, the high-throughput 16S RNA gene sequencing provides detailed information on the taxa comprising of bacterial community. However, it gave little insight into the functional role of the Proteobacteria phylum, especially Campylobacterales, Desulfobacterales and Hydrogenophilales. Future research will be of interest in pursuing a deeper understanding of the metabolism and diversity of this phylum.

\subsection{Correlation between Bacterial Community Structure and PAH Content and TOM}

The redundancy analysis (RDA) ordination diagram is plotted in Figure 6a. The goodness of fit statistics for environmental variables showed that the ordination was highly correlated with TOM, Ace, Fle and other PAHs $(p<0.05)$ with long arrows (Figure 6a). Among the environmental factors, TOM, Ace, Chr and Fle were highly correlated with Axis 1, which explained most of the variations in the bacterial community. This is not surprising because TOM was shown to be correlated with PAH concentration, as revealed in Figure 2. The arrows of TOM and Ace were longer, indicating that they were the most important variables regarding bacterial community ordination. The TOM 
content was highly correlated with bacterial community structures in site px (Figure 6a). Fle, Phe and Anth distinguished the bacterial community of site hr from other sites (Figure 6a). Moreover, bacterial communities of sites hr and yz showed more distinctions compared with other sites with different PAHs contents as revealed in Figure 6a. Other environmental factors such as $\mathrm{pH}$ and EC values have been measured too. However, no regularity has been found between $\mathrm{pH}, \mathrm{EC}$ values and variation of bacterial phyla (data not shown). RDA ordination showed several OTUs of Proteobacteria particularly characterized some communities according to the bacterial community composition (Figure 6b). Sites px, qt and dt were associated with OTUs belonging to Deltaproteobacteria and Gammaproteobacteria classes: Entotheonellaceae (OTU0004), Syntrophobacteraceae (OTU0017), Piscirickettsiaceae (OTU0005 and OTU0007) and Sinobacteraceae family (OTU0015). Site hm was characterized by OTUs related to Alphaproteobacteria (OTU0001) and Betaproteobacteria classes (OTU00012). Sites hr and yz were related to Deltaproteobacteria (OTU0002 and OTU0003), Betaproteobacteria (OTU0006) and Alphaproteobacteria (OTU0016). The arrows of OTU0001, OTU0002, OTU0003, OTU0005, OTU0006 and OTU0017 were longer, which indicated that these six OTUs were the most important variable OTUs characterizing the sampling sites. The relationship between OTUs and samples showed that the abundance order of OTU0001 in each site was $\mathrm{hm}>\mathrm{yz}>\mathrm{qt}>\mathrm{hr} \approx \mathrm{px}>\mathrm{dt}$. The abundance order of OTU0002, OTU0003 and OTU0006 was hr $\approx \mathrm{yz}>\mathrm{qt} \approx \mathrm{px}>\mathrm{hm} \approx \mathrm{dt}$. The abundance order of OTU0017 in each site was $\mathrm{hm} \approx \mathrm{dt}>\mathrm{qt} \approx \mathrm{px}>\mathrm{hr} \approx \mathrm{yz}$. These results indicated that the Proteobacteria phylum had significantly different compositions among the sampling sites. Moreover, some researches revealed that Betaproteobacteria (Acidovorax, and Hydrogenophaga) might have a crucial role in the early response to PAH exposure 16. Moreover, other authors also revealed groups of phenanthrene, anthracene and pyrene-degrading Proteobacteria [48-50], whose abundance and response to simulated bioremediation was demonstrated by barcoded pyrosequencing [14].

\section{Conclusions}

This work provides important information on the distribution tendency of PAHs and the soil microbial community in soil samples surrounding a few coal-fired power plants. A positive association was found between PAHs and soil organic matter. The most affluent PAH congener of all samples was considered to be the four-ring PAHs. Most PAHs were primarily from coal burning or vehicle exhaust, which may be related to the surrounding coal-fired plants. Shifts in diversity and composition of bacterial community were also defined. Soil organic matter was correlated with PAH concentrations. The correlation between soil organic matter and PAHs concentrations may account for the differences among bacterial communities. Proteobacteria phylum was the most abundant group and had the greatest variation. The obvious changing trend related to Proteobacteria may provide useful information for further research on the relationship between PAHs and bacterial communities. This phylum can be also considered an important biological resource for bioremediation of PAH-contaminated soil.

Supplementary Materials: The following are available online at www.mdpi.com/1660-4601/13/9/878/s1.

Acknowledgments: The authors acknowledge the Project supported by the Fundamental Research Funds for the Central Universities (2014QNA18), the National Natural Science Foundation of China (No. 41472223) and Collaborative Innovation Center for Resource Utilization and Ecological Restoration of Old Industrial Base. We thank Yanjun Ma (University of Illinois at Urbana-Champaign) for polishing the paper.

Author Contributions: Jing Ma, Wangyuan Zhang and Yi Chen performed all the experiments and drafted the manuscript. All authors participated in the design of the study and analysis of results. Fu Chen conceived and coordinated the study.

Conflicts of Interest: The authors declare no conflict of interest.

\section{References}

1. Yunker, M.B.; Macdonald, R.W.; Vingarzan, R.; Mitchell, R.H.; Goyette, D.; Sylvestre, S. PAHs in the Fraser River basin: A critical appraisal of PAH ratios as indicators of PAH source and composition. Org. Geochem. 2002, 33, 489-515. [CrossRef] 
2. Chen, F.; Tan, M.; Ma, J.; Zhang, S.L.; Li, G.; Qu, J.F. Efficient remediation of PAH-metal co-contaminated soil usingmicrobial-plant combination: A greenhouse study. J. Hazard. Mater. 2016, 302, 250-261. [CrossRef] [PubMed]

3. Lima, A.L.; Farrington, J.W.; Reddy, C.M. Combustion-derived polycyclic aromatic hydrocarbons in the environment-A review. Environ. Forensics 2005, 6, 109-131. [CrossRef]

4. Li, J.; Shang, X.; Zhao, Z.; Tanguay, R.L.; Dong, Q.; Huang, C. Polycyclic aromatic hydrocarbons in water, sediment, soil, and plants of the Aojiang River waterway in Wenzhou, China. J. Hazard. Mater. 2010, 173, 75-81. [CrossRef] [PubMed]

5. Kim, K.H.; Jahan, S.A.; Kabir, E.; Brown, R.J. A review of airborne polycyclic aromatic hydrocarbons (PAHs) and their human health effects. Environ. Int. 2013, 60, 71-80. [CrossRef] [PubMed]

6. Zhang, Y.X.; Tao, S. Global atmospheric emission inventory of polycyclic aromatic hydrocarbons (PAHs) for 2004. Atmos. Environ. 2009, 43, 812-819. [CrossRef]

7. Yan, W.; Chi, J.S.; Wang, Z.Y.; Huang, W.X.; Zhang, G. Spatial and temporal distribution of polycyclic aromatic hydrocarbons (PAHs) in sediments from Daya Bay, South China. Environ. Pollut. 2009, 157, 1823-1830. [CrossRef] [PubMed]

8. Tobiszewski, M.; Namieśnik, J. PAH diagnostic ratios for the identification of pollution emission sources. Environ. Pollut. 2012, 162, 110-119. [CrossRef] [PubMed]

9. Larsen, R.K.; Baker, J.E. Source apportionment of polycyclic aromatic hydrocarbons in the urban atmosphere: A comparison of three methods. Environ. Sci. Technol. 2003, 37, 1873-1881. [CrossRef] [PubMed]

10. Philip, R.P. The emergence of stable isotopes in environmental and forensic geochemistry studies: A review. Environ. Chem. Lett. 2007, 5, 57-66. [CrossRef]

11. Li, B.; Feng, C.; Li, X.; Chen, Y.; Niu, J.; Shen, Z. Spatial distribution and source apportionment of PAHs in surficial sediments of the Yangtze Estuary, China. Mar. Pollut. Bull. 2012, 64, 636-643. [CrossRef] [PubMed]

12. Almeida, S.M.; Pio, C.A.; Freitas, M.C.; Reis, M.A.; Trancoso, M.A. Approaching $\mathrm{PM}_{2.5}$ and $\mathrm{PM}_{2.5-10}$ source apportionment by mass balance analysis, principal component analysis and particle size distribution. Sci. Total Environ. 2006, 368, 663-674. [CrossRef] [PubMed]

13. Acosta-Martínez, V.; Dowd, S.; Sun, Y.; Allen, V. Tag-encoded pyrosequencing analysis of bacterial diversity in a single soil type as affected by management and land use. Soil Biol. Biochem. 2008, 40, 2762-2770. [CrossRef]

14. Singleton, D.R.; Jones, M.D.; Richardson, S.D.; Aitken, M.D. Pyrosequence analyses of bacterial communities during simulated in situ bioremediation of polycyclic aromatic hydrocarbon-contaminated soil. Appl. Microbiol. Biotechnol. 2013, 97, 8381-8391. [CrossRef] [PubMed]

15. Silva, Í.S.; Santos, E.C.; Menezes, C.R.; Faria, A.F.; Franciscon, E.; Grossman, M. Bioremediation of a polyaromatic hydrocarbon contaminated soil by native soil microbiota and bioaugmentation with isolated microbial consortia. Bioresour. Technol. 2009, 100, 4669-4675. [CrossRef] [PubMed]

16. Martin, F.; Torelli, S.; Paslier, D.L.; Barbance, A.; Martin, L.F.; Bru, D. Betaproteobacteria dominance and diversity shifts in the bacterial community of a PAH-contaminated soil exposed to phenanthrene. Environ. Pollut. 2012, 162, 345-353. [CrossRef] [PubMed]

17. Storey, S.; Ashaari, M.M.; McCabe, G.; Harty, M.; Dempsey, R.; Doyle, O.; Clipson, N.; Doyle, E.M. Microbial community structure during fluoranthene degradation in the presence of plants. J. Appl. Microbiol. 2014, 117, 74-84. [CrossRef] [PubMed]

18. Bacosa, H.P.; Inoue, C. Polycyclic aromatic hydrocarbons (PAHs) biodegradation potential and diversity of microbial consortia enriched from tsunami sediments in Miyagi, Japan. J. Hazard. Mater. 2015, 283, 689-697. [CrossRef] [PubMed]

19. Drigo, B.; Kowalchuk, G.A.; van Veen, J.A. Climate change goes underground: Effects of elevated atmospheric $\mathrm{CO}_{2}$ on microbial community structure and activities in the rhizosphere. Biol. Fertil. Soils 2008, 44, 667-679. [CrossRef]

20. Oberauner, L.; Zachow, C.; Lackner, S.; Högenauer, C.; Smolle, K.H.; Berg, G. The ignored diversity: Complex bacterial communities in intensive care units revealed by $16 \mathrm{~S}$ pyrosequencing. Sci. Rep. 2013, 3. [CrossRef] [PubMed]

21. Su, X.; Zhang, Q.; Hu, J.; Hashmi, M.Z.; Ding, L.; Shen, C. Enhanced degradation of biphenyl from PCB-contaminated sediments: The impact of extracellular organic matter from Micrococcus luteus. Appl. Microbiol. Biotechnol. 2015, 99, 1989-2000. [CrossRef] [PubMed] 
22. Staley, C.; Unno, T.; Gould, T.J.; Jarvis, B.; Phillips, J.; Cotner, J.B.; Sadowsky, M.J. Application of Illumina next-generation sequencing to characterize the bacterial community of the Upper Mississippi River. J. Appl. Microbiol. 2013, 115, 1147-1158. [CrossRef] [PubMed]

23. Hong, C.; Si, Y.X.; Xing, Y.; Li, Y. Illumina MiSeq sequencing investigation on the contrasting soil bacterial community structures in different iron mining areas. Environ. Sci. Pollut. Res. 2015, 22, 10788-10799. [CrossRef] [PubMed]

24. Cao, X.D.; Wang, X.R.; Zhao, G.W. Assessment of the bioavailability of rare earth elements in soils by chemical fractionation and multiple regression analysis. Chemosphere 2000, 40, 23-28. [PubMed]

25. Greengene. Available online: http://greengenes.secondgenome.com/ (accessed on 21 June 2015).

26. Maliszewska-Kordybach, B. Polycyclic aromatic hydrocarbons in agricultural soils in Poland: Preliminary proposals for criteria to evaluate the level of soil contamination. Appl. Geochem. 1996, 11, 121-127. [CrossRef]

27. Nam, J.J.; Song, B.H.; Eom, K.C. Distribution of polycyclic aromatic hydrocarbons in agricultural soils in South Korea. Chemosphere 2003, 50, 1281-1289. [CrossRef]

28. Thomas, D.B.; Franziska, B.; Andre, D. Polycyclic aromatic hydrocarbons, black carbon, and molecular markers in soils of Switzerland. Chemosphere 2004, 56, 1061-1076.

29. Von Lau, E.; Gan, S.Y.; Ng, H.K. Distribution and source apportionment of polycyclic aromatic hydrocarbons (PAHs) in surface soils from five different locations in Klang Valley, Malaysia. Bull. Environ. Contam. Toxicol. 2012, 88, 741-746.

30. Wang, G.D.; Howard, W.M.; Van, Q. Determination of polycyclic aromatic hydrocarbons and trace metals in New Orleans soils and sediments. Soil Sediment. Contam. 2004, 13, 313-327.

31. Jiang, Y.F.; Wang, X.T.; Wu, M.H. Contamination, source identification, and risk assessment of polycyclic aromatic hydrocarbons in agricultural soil of Shanghai, China. Environ. Monit. Assess. 2011, 183, 139-150. [CrossRef] [PubMed]

32. Zuo, Q.; Duan, Y.H.; Yang, Y. Source apportionment of polycyclic aromatic hydrocarbons in surface soil in Tianjin, China. Environ. Pollut. 2007, 147, 303-310. [CrossRef] [PubMed]

33. Maliszewska-Kordybach, B.; Smreczak, B.; Klimkowicz-Pawlas, A. Monitoring of the total content of polycyclic aromatic hydrocarbons (PAHs) in a rable soils in Poland. Chemosphere 2008, 73, 1284-1291. [CrossRef] [PubMed]

34. Callén, M.S.; Iturmendi, A.; López, J.M.; Mastral, A.M. Source apportionment of the carcinogenic potential of polycyclic aromatic hydrocarbons (PAH) associated to airborne $\mathrm{PM}_{10}$ by a PMF model. Environ. Sci. Pollut. Res. 2014, 21, 2064-2076. [CrossRef] [PubMed]

35. Manoli, E.; Kouras, A.; Karagkiozidou, O.; Argyropoulos, G.; Voutsa, D.; Samara, C. Polycyclic aromatic hydrocarbons (PAHs) at traffic and urban background sites of northern Greece: Source apportionment of ambient PAH levels and PAH-induced lung cancer risk. Environ. Sci. Pollut. Res. 2016, 23, 3556-3568. [CrossRef] [PubMed]

36. Abdi, H. Factor Rotations in factor analyses. In Encyclopedia of Social Sciences Research Methods; Lewis-Beck, M., Bryman, A., Futing, T., Eds.; Sage: Thousand Oaks, CA, USA, 2003.

37. Chen, Y.; Sheng, G.; Bi, X.; Feng, Y.; Mai, B.; Fu, J. Emission factors for carbonaceous particles and polycyclic aromatic hydrocarbons from residential coal combustion in China. Environ. Sci. Technol. 2005, 39, 1861-1867. [CrossRef] [PubMed]

38. Yunker, M.B.; Snowdon, L.R.; Macdonald, R.W.; Smith, J.N.; Fowler, M.G.; Skibo, D.N.; McLaughlin, F.A.; Danyushevskaya, A.I.; Petrova, V.I.; Ivanov, G.I. Polycyclic aromatic hydrocarbon composition and potential sources for sediment samples from the Beaufort and Barents Seas. Environ. Sci. Technol. 1996, 30, 1310-1320. [CrossRef]

39. May, W.E.; Wise, S.A. Liquid chromatographic determination of polycyclic aromatic hydrocarbons in air particulate extracts. Anal. Chem. 1984, 56, 225-232. [CrossRef]

40. Harrison, R.M.; Smith, D.J.T.; Luhana, L. Source apportionment of atmospheric polycyclic aromatic hydrocarbons collected from an urban location in Birmingham, UK. Environ. Sci. Technol. 1996, 30, 825-832. [CrossRef]

41. Sofowote, U.M.; McCarry, B.E.; Marvin, C.H. Source apportionment of PAH in Hamilton harbour suspended sediments: Comparison of two factor analysis methods. Environ. Sci. Technol. 2008, 42, 6007-6014. [CrossRef] [PubMed] 
42. Meckenstock, R.U.; Mouttaki, H. Anaerobic degradation of non-substituted aromatic hydrocarbons. Curr. Opin. Biotechnol. 2011, 22, 406-414. [CrossRef] [PubMed]

43. Sun, R.; Jin, J.; Sun, G.; Liu, Y.; Liu, Z. Screening and degrading characteristics and community structure of a high molecular weight polycyclic aromatic hydrocarbon-degrading bacterial consortium from contaminated soil. J. Environ. Sci. 2010, 22, 1576-1585. [CrossRef]

44. Jones, M.; Rodgers-Vieira, E. Association of growth substrates and bacterial genera with benzo[a]pyrene mineralization in contaminated soil. Environ. Eng. Sci. 2014, 31, 689-697. [CrossRef] [PubMed]

45. Handley, K.M.; Wrighton, K.C.; Piceno, Y.M.; Andersen, G.L.; DeSantis, T.Z.; Williams, K.H. High-density PhyloChip profiling of stimulated aquifer microbial communities reveals a complex response to acetate amendment. FEMS Microbiol. Ecol. 2012, 81, 188-204. [CrossRef] [PubMed]

46. Zhao, H.P.; Ilhan, Z.E.; Ontiveros-Valencia, A.; Tang, Y.; Rittmann, B.E.; Krajmalnik-Brown, R. Effects of multiple electron acceptors on microbial interactions in a hydrogen-based biofilm. Environ. Sci. Technol. 2013, 47, 7396-7403. [CrossRef]

47. Ruiz, V.; Ilhan, Z.E.; Kang, D.W.; Krajmalnik-Brown, R.; Buitrón, G. The source of inoculum plays a defining role in the development of MEC microbial consortia fed with acetic and propionic acid mixtures. J. Biotechnol. 2014, 182-183, 11-18. [CrossRef] [PubMed]

48. Singleton, D.R.; Sangaiah, R.; Gold, A.; Ball, L.M.; Aitken, M.D. Identification and quantification of uncultivated Proteobacteria associated with pyrene degradation in a bioreactor treating PAH-contaminated soil. Environ. Microbiol. 2006, 8, 1736-1745. [CrossRef] [PubMed]

49. Ma, J.; Xu, L.; Jia, L.Y. Degradation of polycyclic aromatic hydrocarbons by Pseudomonas sp. isolated from active sewage sludge of chemical plant. J. Environ. Sci. 2012, 24, 2141-2148. [CrossRef]

50. Ma, J.; Xu, L.; Jia, L.Y. Characterization of pyrene degradation by Pseudomonas sp. strain Jpyr-1 isolated from active sewage sludge. Bioresour. Technol. 2013, 140, 15-21. [CrossRef] [PubMed]

(C) 2016 by the authors; licensee MDPI, Basel, Switzerland. This article is an open access article distributed under the terms and conditions of the Creative Commons Attribution (CC-BY) license (http://creativecommons.org/licenses/by/4.0/). 